\title{
The analysis of space junk clean-up program based on Fuzzy preference decision time-dependent model based on entropy weight and ameliorative AHP
}

\author{
Xinyue Tantai \\ School of North China Electric Power University, Baoding 071000, China; \\ 604798211@qq.com
}

Keywords: Space debris, AHP, Entropy weight

\begin{abstract}
NASA demonstrated that there are more than 500,000 pieces of space debris around the earth. It is necessary to remove the space junk because they do great harm to the aircraft. How to remove the space junk has become a universal concern..In this paper, two models are established to determine commercial opportunity for private firm and to find the best alternative to remove the space junk.

Fuzzy preference decision time-dependent model based on entropy weight and ameliorative AHP are applied to determine the best alternative or combination of alternatives that a private firm could adopt as a commercial opportunity to address the space debris problem. We analyze and calculate the costs, risks, equipment life, the number of space junk which can be cleared and profit operation of space elevator, small satellites, applications of current and magnetic and laser broom to get a best method.
\end{abstract}

\section{Model for choosing best alternative to remove space junk}

\subsection{Relative membership degree}

\section{$>$ Quantitative data}

Assuming $\mathrm{F}=\{\mathrm{f} 1, \mathrm{f} 2, \ldots \mathrm{fn}\}$ as $\mathrm{n}$ sets proposed schemes, $\mathrm{Z}=\left\{\mathrm{z}_{1}, \mathrm{z}_{2}, \ldots, \mathrm{z}_{\mathrm{m}}\right\}$ as indicators of comprehensive evaluation system and $\mathrm{X}=\left(\mathrm{x}_{\mathrm{ij}}\right)_{\mathrm{m} \times \mathrm{n}}$ as eigen values of $\mathrm{m}$ corresponding indicators.xij represents the first $j$ sub-index value of the $i$-th program.

In general, there are many types of evaluation index. Dimension of each index is not uniform and optimization criteria are not same, so the original index value shall be standardized. The standardized parameter values not only eliminate the effect of dimension , but also measure the merits of scale, so can make it as the relative membership degree matrix R.

(1) benefit-oriented

(2) cost-type

$$
r_{i j}=\frac{x_{i j}}{x_{\max }}
$$

$$
r_{i j}=\frac{x_{\min }}{x_{i j}}
$$

\section{$>$ Type of qualitative data}

(1) To quantify the qualitative index of language

In the multi-attribute decision-making problems, the attribute of decision making is generally divided into the category of income attribute (the bigger the value is, the better the property index) and the cost attribute index (the smaller the value is better). And the two types of attribute indicators usually have two different forms of expression, which are quantitative and qualitative. For qualitative indicators bipolar proportional method[1] can be used to convert it into quantitative indicators, the

specific form of transformation are shown in table 1. 
Table 1 Bipolar proportion method for the conversion of qualitative indicators to quantitative indicators

\begin{tabular}{l|c|c|c|c|c|c|c}
\multicolumn{1}{c|}{} & & & & & & & \\
Quantity value & 0 & 1 & 3 & 5 & 7 & 9 & 10 \\
\hline Cost attribute & highest & higher & high & general & low & lower & lowest \\
\hline Income attribute & lowest & lower & low & general & high & higher & highest \\
\hline
\end{tabular}

When all of the attributes are all changed into numerical data , the data matrix is set $\mathrm{X}=\left(\mathrm{x}_{\mathrm{ij}}\right)_{\mathrm{m} \times \mathrm{n}}$

(2) Property index a normalized

Use range transform form to normalize processing of all the attributes.

For the income attribute index, the normalized formula is:

$$
r_{i j}=\frac{x_{i j}-\min \left(x_{j}\right)}{\max \left(x_{j}\right)-\min \left(x_{j}\right)}
$$

For the cost attribute index, the normalized formula is:

$$
r_{i j}=\frac{\max \left(x_{j}\right)-x_{i j}}{\max \left(x_{j}\right)-\min \left(x_{j}\right)}
$$

In the formula: $\quad \max \left(\mathrm{x}_{\mathrm{j}}\right)=\max \left\{\mathrm{x}_{1 \mathrm{j}}, \mathrm{x}_{2 \mathrm{j}}, \ldots, \mathrm{x}_{\mathrm{mj}}\right\} ; \min \left(\mathrm{x}_{\mathrm{j}}\right)=\min \left\{\mathrm{x}_{1 \mathrm{j}}, \mathrm{x}_{2 \mathrm{j}}, \ldots, \mathrm{x}_{\mathrm{mj}}\right\}$

$$
\mathrm{i}=1,2, \cdots, \mathrm{m} ; \mathrm{j}=1,2, \cdots, \mathrm{n}
$$

The relative membership degree matrix is obtained from the $r_{i j}$ aggregate obtained in the preparatory work. $\mathrm{R}=\left[\begin{array}{ccc}\mathrm{r}_{11} & \cdots & \mathrm{r}_{1 \mathrm{n}} \\ \vdots & \ddots & \vdots \\ \mathrm{r}_{\mathrm{m} 1} & \cdots & \mathrm{r}_{\mathrm{mn}}\end{array}\right]$

\subsection{Determination of index weight}

\section{$>$ Improvement of AHP}

The three scale AHP method is a simplified algorithm based on the traditional AHP method. It reduces the decision-makers in determining the relative importance of indicators fuzziness and it reduced the number of indicators pairwise comparison. Part of the judgment matrix elements may be directly deduced from the other elements, and automatically satisfy the conformance requirements. The calculation steps are as follows:

(1) Establish judgment matrix C

$$
c_{i j}=\left\{\begin{array}{cc}
1 & \text { i index is more important than the j index } \\
0 & \text { i index and j index as important } \\
-1 & \text { j index is more important than the i index }
\end{array} \quad \forall i, j\right.
$$

(2) Optimal transfer matrix of judgment matrixD

$$
\mathrm{d}_{\mathrm{ij}}=\frac{1}{\mathrm{~m}} \sum_{\mathrm{k}=1}^{\mathrm{m}}\left(\mathrm{c}_{\mathrm{ik}}+\mathrm{c}_{\mathrm{kj}}\right) \quad, \quad \forall \mathrm{i}, \mathrm{j}
$$

(3) Consistency judgment matrix $\mathrm{A}$

$$
a_{i j}=\exp \left(d_{i j}\right) \quad, \quad \forall i, j
$$

(4) A calculation of the normalized feature vector w (using the plot method), as the relative weights of each index $w_{0}$

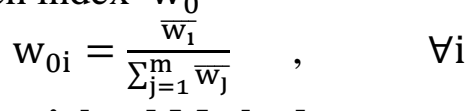

\section{Entropy-weighted Method}

Entropy is used as a measure of uncertainty and information in information theory:

$$
\mathrm{S}\left(\mathrm{P}_{1}, \mathrm{P}_{2}, \cdots, \mathrm{Pn}\right)=-\mathrm{k} \sum_{\mathrm{i}=1}^{\mathrm{n}} \mathrm{p}_{\mathrm{i}} \times \ln \left(\mathrm{p}_{\mathrm{i}}\right) \quad \forall \mathrm{i}
$$


In the formula: $\mathrm{k}$ is a positive constant and let $\mathrm{k}=\frac{1}{\ln (\mathrm{n})}$.

$\mathrm{p}_{\mathrm{i}}$ is a discrete probability distribution.

The set of indicators $z_{j}$ projective $p_{i j}$ can be defined as:

$$
\mathrm{p}_{\mathrm{ij}}=\frac{\mathrm{x}_{\mathrm{ij}}}{\sum_{\mathrm{i}=1}^{\mathrm{n}} \mathrm{x}_{\mathrm{ij}}} \quad, \quad \forall \mathrm{i}, \mathrm{j}
$$

Entropy $\mathrm{E}$ and entropy-weighted $\mathrm{w}_{\mathrm{j}}^{\prime}$ is calculated according to the following formula:

$$
\begin{array}{ll}
\mathrm{E}_{\mathrm{j}}=-\frac{1}{\ln (\mathrm{n})} \sum_{\mathrm{i}=1}^{\mathrm{n}} \mathrm{p}_{\mathrm{ij} \times \ln \left(\mathrm{p}_{\mathrm{ij}}\right),} & \forall \mathrm{j} \\
\mathrm{w}_{\mathrm{j}}^{\prime}=\frac{1-\mathrm{E}_{\mathrm{j}}}{\mathrm{n}-\sum_{\mathrm{j}=1}^{\mathrm{n}} \mathrm{E}_{\mathrm{j}}}, \quad, & \forall \mathrm{j}
\end{array}
$$

Entropy weight is an objective weighting method and independent of people's preferences and experience, in order to retain the experts and decision makers, taking into account the subjective and objective two aspects. It can be combined with the aforementioned improved AHP method. Entropy weight is actually a priori subjective weight of a correction. Apparent $w_{0}$ of the 5.2.1 for a priori weight, entropy weight $w_{j}^{\prime}$ for the posterior weight, the combination of weights $w_{j}$ :

$$
w_{j}=\frac{w_{0} \times w_{j}^{\prime}}{\sum_{j=1}^{n}\left(w_{0} \times w_{j}^{\prime}\right)},
$$

\subsection{Relative membership degree}

Applying the principle of fuzzy comprehensive evaluation, the relative optimal membership degree vector: $\mathrm{u}=\mathrm{R} \times \mathrm{w}$

According to the comparison of relative membership value of each scheme, in descending order.

\section{Model Application}

Use Fuzzy Preference Decision Method Based on Entropy Weight and Ameliorative AHP to determine the best alternative or combination of alternatives that a private firm could adopt as a commercial opportunity to address the space debris problem.

Meanwhile, time is the basis for the formation of the economic benefits and the length of time in economic activity significantly affect economic height. The more time is spent in economic activity, the more economic benefits we will get. On the contrary, the less time is spent in economic activity, the less economic benefits we will get. Assuming that the economic activities of all programs have same time so the establishment of the model is based on the time.

We can analyze and calculate the costs, risks, equipment life, the number of space junk which can be cleared and profit operation of space elevator, small satellites, applications of current and magnetic and laser broom to get a best method .

Assuming that we can get same profit by clearing the same amount of garbage these different methods and taking into account other factors, We can assume a profit.

Fist, get a qualitative analysis of risks, equipment life, the number of space junk which can be cleared .

\begin{tabular}{c|ccc}
\hline & risk & $\begin{array}{c}\text { Equipment } \\
\text { life }\end{array}$ & $\begin{array}{c}\text { The number } \\
\text { of space } \\
\text { junk }\end{array}$ \\
\hline $\begin{array}{c}\text { Space elevator } \\
\text { Small satellites }\end{array}$ & higher & general & general \\
higher & general & high \\
$\begin{array}{c}\text { Applications of current } \\
\text { and magnetic }\end{array}$ & higher & higher & high \\
Laser broom & high & higher & general \\
\hline
\end{tabular}




\begin{tabular}{|c|c|c|c|c|c|}
\hline & \begin{tabular}{|rr}
\multicolumn{2}{c}{ Cost(hundre } \\
d & million \\
dollars) &
\end{tabular} & Risk & Equipment life & $\begin{array}{l}\text { The } \\
\text { number of } \\
\text { space junk }\end{array}$ & $\begin{array}{l}\text { Profit(hu } \\
\text { ndred } \\
\text { million } \\
\text { dollars) }\end{array}$ \\
\hline $\begin{array}{l}\text { Space } \\
\text { elevator }\end{array}$ & 2.4 & 1 & 5 & 5 & 2.6 \\
\hline $\begin{array}{r}\text { Small } \\
\text { satellites }\end{array}$ & 1 & 1 & 5 & 7 & 6 \\
\hline $\begin{array}{l}\text { Application } \\
\text { s of current } \\
\text { and magnetic }\end{array}$ & 0.05 & 1 & 9 & 7 & 6.95 \\
\hline Laser broom & 2 & 3 & 10 & 5 & 3 \\
\hline
\end{tabular}

Make the above qualitative indicators into quantitative indicators by Bipolar ratio method ,and combined with other quantitative indicators to have the following table.

We make all attributes indicators go through normalization processing by Range transformation to have the following matrix

Then, establish judgment matrix C. Due[6]to a different focus when judging there are many different matrix $C$. Here we focus on several different judgment matrix $C$ to calculate the results, and get conclusion.

\section{Conclusion}

We use the Ameliorative AHP model to choose the best alternative. The method, although it can effectively solve our problems, but due to the lacking of data, we can only evaluate the problem by the fuzzy algorithm. A mount of subjective factors will be add into model. We combine different algorithm to reduce the effects of subjectivity. But it still exists .In the future, we need more effective data to debug and improve our model ,which makes the model more optimized.

\section{References}

[1]Sun Ganget al: evaluation of the orbital debris model of the European Space Agency2000 fourth (total 65)

[2]Chen Dan: clean space road "stumbling block" [J] new science fiction (Abstract Edition) 2011 (6)

[3]Si Shou Kuiet al:Mathematical modeling algorithm and its application, National Defence Industry Press, chapter 8.

[4] Shen Jianminget al. Project risk management [M]. Beijing: Mechanical Industry Press,,2004( 6)

[5]1. Dept . of Math, Huanggang Normal University , Huangzhou 438000 , China ; 2.School of Sciences, WUT, Wuhan 430070 , China

[6] Xie Rong Where a minimum cost maximum flow algorithm of transportation network seek [J] Operations Research and Management, 2000, 9 (4): 33238.

[7] Jiang Qiyuanet almathematical model [M] 2nd ed. Beijing: Higher Education Press, 2001.3052324 